\title{
Field measurements and CFD simulation of a room in an elderly care center in Lithuania to evaluate air quality and thermal comfort
}

\author{
Mantas Dobravalskis ${ }^{1, *}$, Lina Šeduikyte $\dot{1}^{1}$, and Ugne Didžiariekyte $\dot{~}^{1}$ \\ ${ }^{1}$ Kaunas University of Technology, Faculty of Civil Engineering and Architecture, Studentu str. 48, 51367, Kaunas, Lithuania
}

\begin{abstract}
Aging is one of the biggest challenges that our society will face in the next decades to come. Multiple sources predict that the number of elderly people will rapidly increase in a lot of regions around the world. In Europe alone it is estimated that the number of elderly people will increase by up to 5 times in the next 30 years. With a growing number of elderly people, the importance of taking care of them also grows. Therefore, we need to make sure that the conditions they live in are suitable for their specific needs: both comfort vise and health vise.

To evaluate the current situation and issues in elderly care centers field measurements were taken in ECC in Kaunas, Lithuania. During these measurements, data were collected about temperature and relative humidity at multiple rooms in the care center. Gathered data was analyzed and major issues were noticed. The second stage of this study included CFD simulations of one of the rooms that ECC residents live in. Currently, this building only has natural ventilation in all of its rooms. Mechanical ventilation was simulated to see how it would impact air quality and thermal comfort in such rooms. Two main types of ventilation were simulated: mixing ventilation and displacement ventilation. Both methods were compared to natural ventilation and each one was evaluated as a potential solution for solving current issues in elderly care centers. It is also important to make sure that the solution chosen is sustainable and can be widely implemented.
\end{abstract}

\section{Introduction}

The indoor environment is getting more and more attention in the scientific community and by public as indoor air quality (IAQ) and thermal comfort (TC) has a big impact on people's health and comfort [1]. Studies show that on average a person spends around $87 \%$ of their time indoors [2]. Elderly people tend to spend even more time indoors and due to their weak immune system [3], they are more sensitive to bad IAQ and TC. There will be around 219 million people aged over 65 years old in the European Union alone by the year 2050,30\% of the whole population will be elderly [4]. As the number of older people steadily increases around the world number of dedicated nursing homes will also increase [5].

As mentioned before old people spend most of their time indoors. As they get older various diseases, weakness and disabilities lower their independence and the option to go outside is greatly reduced. This is also true for people living in elderly care centers (ECC). Even though nurses working in them do their best to take care of each of the residents as well as they can, time spent outdoors is very limited. This is especially true during the winter month. Due to cold temperature and weaker immune system going outside in cold weather can have a big impact on people's health and wellbeing [6]. Big difference in temperature between seasons also has other impacts on a persons health. A study shows that during winter, low ambient temperature can induce large fluctuations in blood pressure as well as other changes in humans' body [7]. Being inside of their rooms for such a big part of their day also means that pollutants, temperature and other factors can have a very big impact on resident's health [8]. Even worse, bad air quality can result in a noticeable increase in mortality rate as well [9].

There are multiple studies that prove that elderly people need different conditions when compared to younger adults [10, 11]. With age, humans body undergoes various changes and with them comes different requirements for their environment. Usually, older people have slower metabolic rates and the body produces less heat [12]. Furthermore, older people are less sensitive to changing temperature in their environment [13]. Due to this reason, they can't regulate their bodies temperature as effectively as young people. Elderly people have reduced warmth sensitivity during winter and cold sensitivity

* Corresponding author: mantas.dobravalskis@ktu.edu 
during summer [14]. Even though this is accepted in the scientific community Lithuania as well as other countries doesn't have specialized norms just for elderly people or ECC. The norms that are used in Lithuania at the moment [15] only specify that reference levels for both temperature and relative humidity should be used from the general norms [16]. These norms are used for all residential and public buildings.

One of the many effects of climate change is global warming and unpredictable weather. Lately, there is an increasing number of unusually hot or cold periods that was uncommon in Lithuania before. Being north climate country, most buildings in Lithuania is highly insulated. While this is a great advantage during the winter, it can cause serious issues during the summer period. It is also worth mentioning that almost no buildings in Lithuania have air conditioning in them. Traditionally people were more concerned with keeping the building warm, not cooling them down. Badly designed buildings with large windows and no shadow covers can become too hot during the summer month due to this reason. High temperatures inside can cause not only discomfort but also serious threat to the health of its residents and even increased mortality [17]. It is also the case with ECC. Another study shows that heat waves and overheating is especially dangerous to the elderly residents [18]. They are less sensitive to ambient conditions and can't regulate their body temperatures as well as younger people.

While field measurements are a great method to evaluate IAQ and TC, in order to more closely understand how the airs circulates the room, computational fluid dynamics (CFD) simulations can also be used. This method allows to not only better understand the current situation in ECC, but to also simulate potential ways to improve indoor environment. This method is widely used by scientific community in various fields. CFD simulations can be used to optimize airflow patterns for the best IAQ. Such study has been carried out by C. Méndez in 2008 [19]. Using this technique optimal ventilation airflow patterns were found in a hospital room. Studies using CFD was also used to analyse air change efficiency, contaminant removal and thermal comfort [20, 21]. Well designed HVAC system is the main factor that impacts indoor environment. But it requires to take into consideration a lot of variables like positions of inlet and outlet, quantity of air, extraction rate, etc. All these variables can be tested and optimized using CFD.

The goal of this study is to measure current conditions in ECC during summer and winter; analyse if they are suitable for people over 65 and compare them to national reference levels. When these results are analysed the same room that the measurements were carried out in will me simulated using CFD. During this stage current natural ventilation will be compared to mechanical mixing and displacement ventilation methods. These results will be interpreted, and the best option selected.

\section{Methodology}

This study carried out field measurements in one of ECC in Lithuania. ECC selected is in the second-largest city in Lithuania - Kaunas. Its location can be seen in fig. 1.

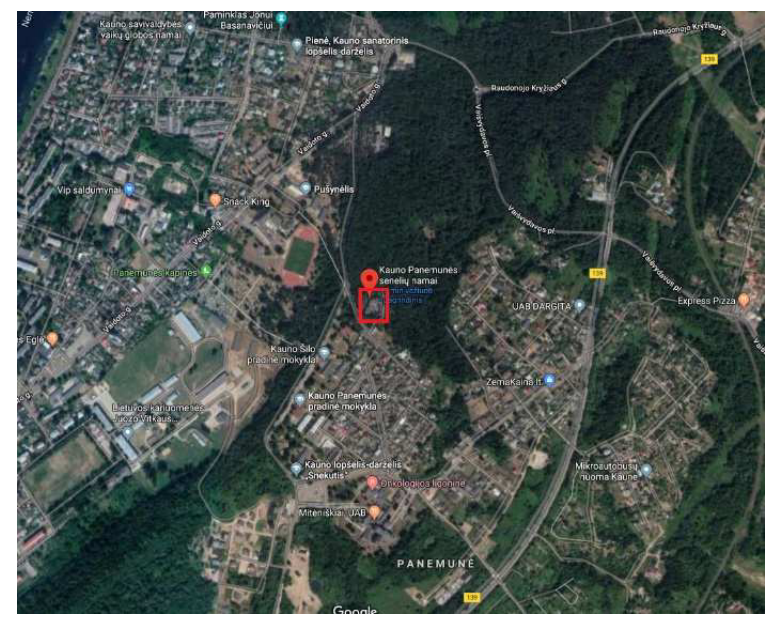

Fig. 1. Location of "Kauno Panemune social care center" in Kaunas, Lithuania

ECC is located near the edge of the city. There is no major industrial activity nearby. It is mostly surrounded by forests and low-density residential district. Most of the houses in that district is heated using solid fuel. This might be a big pollutant during winter months and has to be taken into account as well. ECC itself is a 3-story building. First, two floors are mainly used for private rooms of its residents, while the third floor is used as a daycare center where people take classes, exercises and participates in other leisure activities.

There are two major types of rooms in the building: single and double rooms. Some of the single rooms are also intensive care rooms. People living in these rooms can't walk and have serious health problems, therefore, need constant help from the nurses. The average area of a single room is $12 \mathrm{~m}^{2}$, while doable rooms area on average is $24 \mathrm{~m}^{2}$.

The building had some recent renovations done, but no major improvements was done to the HVAC system. The building is heated using a central heating system and radiators placed under the windows in all the rooms. All the private rooms have natural ventilation. Only some of the common areas had mechanical ventilation installed. This is a typical setup for ECC's in Lithuania. All rooms analysed in our study had windows in them that the residents could close and open as they like or ask nurses to do that for them. None of the rooms had air conditioning or ability to adjust heating power.

\subsection{Field measurements}

All field measurements were done twice: during summer and winter. The methodology for both seasons remained the same. Winter measurements were taken in February 2019. Summer measurements were carried out in August 
of 2019. Measurements were taken in both single and double rooms, but only data from double rooms will be used in this study. There was a total of 12 double rooms that the measurements were taken in.

During the field measurements air temperature, relative humidity $(\mathrm{RH})$, and $\mathrm{CO}_{2}$ concentration were measured. Temperature and relative humidity $(\mathrm{RH})$ were measured using "HOBO MX1101" data loggers $( \pm 0.2 \circ \mathrm{C}$, $\pm 2 \% \mathrm{RH}$ accuracy). $\mathrm{CO}_{2}$ level was measured using "FLUKE 975 AirMeter". Temperature and RH sensors were placed at 3 different heights at the same spot. These heights were chosen to represent feet level at 0.1 meters; humans head level when laying down at 0.6 meters and humans head level when sitting down at 1.1 meters. $\mathrm{CO}_{2}$ was measured in 2 of the rooms at 0,8 meters above the floor.

Stands with all 3 sensors were placed in a way to get the most accurate results possible. They were placed at least 1 meter away from any walls, windows, doors, heat sources or other objects that could cause an error in the data. All rooms had residents in them while the data was collected.

Data logging equipment was left in the rooms for a total time of 35 minutes. First 25 minutes of the data were not used in further analyses. This time period was used to reach steady-state in the rooms. When placing sensors multiple people would enter the room and place the equipment. This can cause some disturbance to the natural conditions in the room. After steady-state was reached, the next 10 minutes of data were logged and analyzed in this study. Data was logged in a 1-minute interval. $\mathrm{CO}_{2}$ measurements were taken as an average value of the 10 minutes period. Due to technical problems, $\mathrm{CO}_{2}$ was only measured during summer field measurements.

\subsection{Computational fluid dynamics simulation}

CFD simulations will be used to both better evaluate natural ventilation that is currently used in the rooms and compare it to mechanical ventilation. There will be 2 main mechanical ventilation methods used: mixing ventilation and displacement ventilation. Both methods are widely used in big variety of buildings and use cases. Specialised commercial CFD software FloVENT (Mentor Graphics, United States) was used. It can be used to calculate and visualize various airflow, temperature distribution, contaminants, solar impact and other parameters. LVEL $\mathrm{k}-\varepsilon$ turbulence model was used in this study. This model is widely used in scientific community and is a great selection for simulating indoor airflow, contaminants concentrations and temperatures. To measure the effectiveness of the ventilation system, local mean age (LMA) was calculated as well. Lack of fresh air is one of the most common reasons for people complaining about their indoor environment. As this buildings doesn't use any recirculation, all air that is supplied to the rooms is fresh air from the outside. LMA calculates the time needed for a fresh air to reach specific point in space.
LMA values are expressed in minutes and is great indicator of dead spots in the room where air circulation is too slow. CFD simulations were performed for summer and winter conditions. The goal of these simulations was to visualize temperature distribution in the room at different heights and visualize LMA values in the rooms. A double-precision solver of Flovent was used to achieve steady-state simulation results.

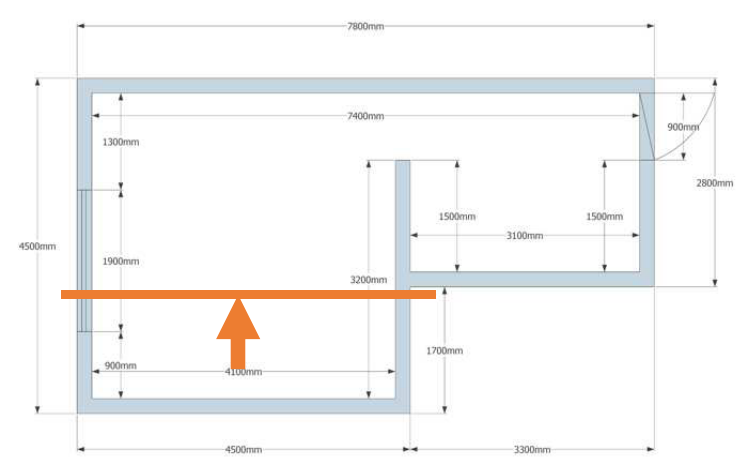

Fig. 2. Floor plan of a typical double room in ECC studied. The orange line shows section used for visualizing temperature distribution.

Simulations will be carried out in a standard double room. Most of the rooms are almost identical and only minor things like furniture layout is different between them. A Plan of a double room can be seen in fig. 2. 3D model of the rooms was made using plans of the building as well as observations done during field measurements. As mentioned before residents were in the rooms during the field measurements stage room was modeled with 2 residents laying down in their beds. The room also had two beds, a table, large wardrobe, cabinet, window and radiator modeled. Solar radiation wasn't analyzed in this study. The only difference between winter and summer cases was the activation of radiator as well as changing ambient temperatures that represent that season the best. A 3D model of the room is shown in Fig. 3.

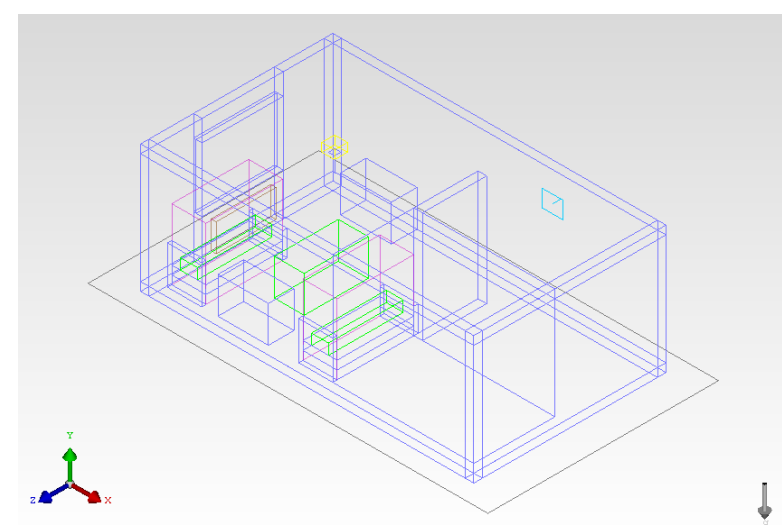

Fig. 3. Isometric view of rooms geometry used in computational fluid dynamics (CFD) simulation. 
The mechanical mixing ventilation model was built using a swirl diffuser mounted in the ceiling at the center of the room. A grill at the top of the room was used as an outlet. Exhaust grill was placed as far from the intel as possible.

Mechanical displacement ventilation was modeled using a grill at the ceiling as an outlet. The intel was modeled as a diffuser placed at the bottom of the room, 0.2 meters from floor level.

The position of inlets and outlets for both mechanical ventilation methods can be seen in Fig.4.

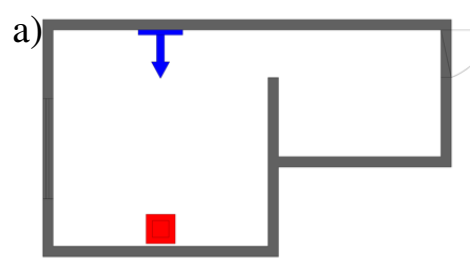

b)

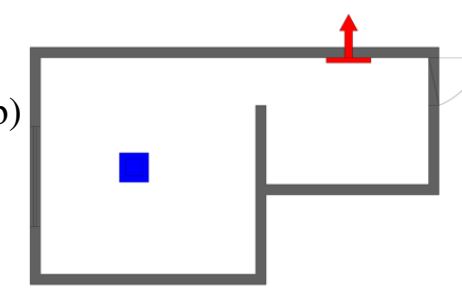

Fig. 4. Position of inlets (Blue) and outlets (Red): a) displacements ventilation; b) mixing ventilation.

All boundary conditions replicated values measured during field measurements. Internal wall temperature was set to $21^{\circ} \mathrm{C}$ during both seasons. External wall temperature was lowered to $17^{\circ} \mathrm{C}$ for the winter season, while internal wall temperature was kept the same. Ambient outside temperature was set at $25^{\circ} \mathrm{C}$ during the summer, and at $5^{\circ} \mathrm{C}$ during the winter. Supply airflow was set to $150 \mathrm{~m} 3 / \mathrm{h}$ in all cases. This relatively high airflow was selected to prevent overheating during summer. In all simulated cases exhaust grilles were modelled with $150 \mathrm{~m} 3 / \mathrm{h}$ air flow and 1.0 free area. A source cuboid was designed to represent a heating source with a constant power of $700 \mathrm{~W}$. Heating due to lighting was modelled due to low power and relatively efficient lights used. Ambient $\mathrm{CO}_{2}$ concentration was set to 400ppm.

An option for variable Cartesian grid was used to divide the geometry into regions. To get more accurate results grids density was increased near air inlets, heat source,

\section{Results}

\subsection{Field measurements}

Average temperature and relative humidity during both seasons can be found in Table.1. Results show that temperature during the summer is highest at 1.1 meters from the floor and is equal to $24.25^{\circ} \mathrm{C}$. The lowest temperature was recorded at 0.1 meters height during the winter. It was as low as $19,47^{\circ} \mathrm{C}$. Average temperature between all 3 heights in summer was $24.14^{\circ} \mathrm{C}$, while during the winter it was $20.17^{\circ} \mathrm{C}$. The lowest temperature recorded during the field measurements was only $17,52^{\circ} \mathrm{C}$ ( 0.1 meters). The highest temperature of $26,17^{\circ} \mathrm{C}(1.1$ meters) was reached during summer. So even though average temperatures are reasonable, some of the rooms had some issues with it being too height during the summer and too low in the winter. Such a low temperature in some of the rooms can cause discomfort and even respiratory tract illness. Biggest temperature gradient was recorded during winter. In one of the room temperature difference was $1.91^{\circ} \mathrm{C}$ between 0.1 meters data and 1.1 meters data.

Relative humidity results are typical for both seasons. During summer air is a lot moister than during winter months. Average RH in the summer was 55,37\%, in some cases, it was as high as 74,69\%. During the winter RH was only 37,12 , and in some cases was as low as $23,4 \%$. These are common issues in the northern climate. Too moist of an air can cause a spread of infections, mold growth and discomfort. Very low RH, on the other hand, can cause dry skin, eye itching, allergy development and respiratory tract irritation. Problems with RH values being not suitable for its residents is mainly caused by the HVAC system that is not working efficiently. This indicates that the natural ventilation system used now can't control RH in the rooms efficiently.

Table. 1 Average temperature and $\mathrm{RH}$ during summer and winter

\begin{tabular}{|c|c|c|c|c|c|}
\hline $\begin{array}{c}\mathbf{T}_{\mathbf{0}, \mathbf{1}}, \\
{ }^{\mathbf{C}}\end{array}$ & $\begin{array}{c}\mathbf{T}_{\mathbf{0}, \mathbf{6}}, \\
{ }^{\mathbf{0}} \mathbf{C}\end{array}$ & $\begin{array}{c}\mathbf{T}_{\mathbf{1}, \mathbf{1}}, \\
{ }^{\mathbf{C}} \mathbf{C}\end{array}$ & $\begin{array}{c}\mathbf{R H}_{\mathbf{0}, \mathbf{1}}, \\
\mathbf{\%}\end{array}$ & $\begin{array}{c}\mathbf{R H}_{\mathbf{0}, \mathbf{6}}, \\
\mathbf{\%}\end{array}$ & $\begin{array}{c}\mathbf{R H}_{\mathbf{1 , 1},} \\
\mathbf{\%}\end{array}$ \\
\hline \multicolumn{6}{|c|}{ Summer - August, 2019} \\
\hline 24,02 & 24,14 & 24,25 & 52,57 & 56,87 & 56,67 \\
\hline \multicolumn{6}{|c|}{ Winter - February, 2019 } \\
\hline 19,47 & 20,10 & 20,93 & 36,55 & 39,67 & 35,14 \\
\hline
\end{tabular}

A comparison between field measurements results and National Lithuanian norms can be seen in Fig.5. results are within national reference levels in all cases and only looking at specific rooms and specific heights there are few points with values that are outside of these limits. As mentioned before there are no specialized norms for elderly people, and the gaps between minimum and maximum allowed values are relatively high. Both minimum $\mathrm{RH}$ and temperature allowed is the same during both seasons. The minimum temperature allowed is $18^{\circ} \mathrm{C}$, minimum $\mathrm{RH}$ value is $35 \%$. Maximums temperature allowed in summer is $28^{\circ} \mathrm{C}$, during winter this limit is lowered to $22^{\circ} \mathrm{C}$. Maximum $\mathrm{RH}$ allowed during the summer is $60 \%$ and can be $5 \%$ higher during the winter. 


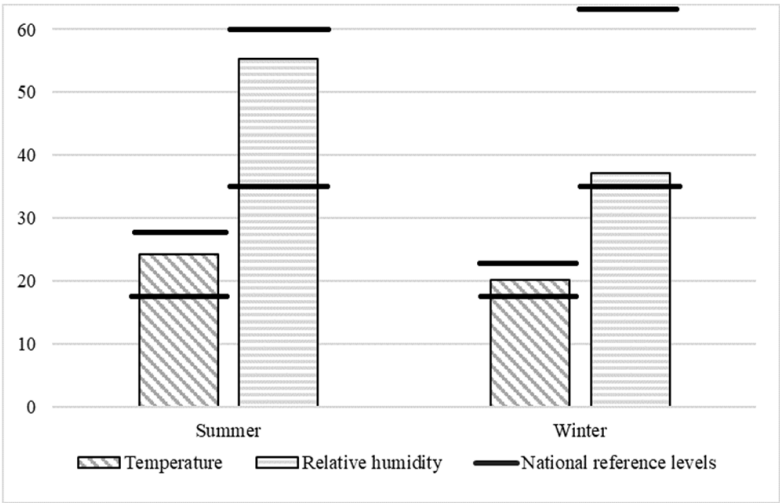

Fig. 5. Average temperature and RH compared to national reference levels: summer and winter.

Lack of more specific norms can result in conditions that aren't suitable for specific social groups, in this case, people over 65. This is true with PMV calculations as well. It is a great way to evaluate thermal comfort in the general public, but when it comes to specific groups and cases the results it shows can be unreliable. Therefore, this parameter wasn't calculated in this study.

$\mathrm{CO}_{2}$ values in all the rooms tested were almost the same, average concentration was $577 \mathrm{ppm}$. This is significantly lower values than expected. It might be due to windows being opened recently. Further analyses would be required to better evaluate the concentration of $\mathrm{CO}_{2}$ and other contaminants.

\subsection{Computational fluid dynamics simulation}

CFD simulations were carried out for a total of 6 cases:

- Summer

- Natural ventilation

○ Mechanical mixing ventilation

○ Mechanical displacement ventilation

- Winter

- Natural ventilation

○ Mechanical mixing ventilation

- Mechanical displacement ventilation

Table. 3 compares all 3 ventilation methods to each other during both seasons. Main factors compared is temperature distribution in the room during both seasons as well as LMA during winter.

Natural ventilation showed the worst results. Air circulation in the rooms was very limited in this case. Areas further away from intel/outlet had high LMA value. These values were a lot higher in the main room as well. Temperature was uneven throw-out the room. Heat from the radiator struggled to reach other side of the room. During the winter heat from the radiator didn't circulated the room effectively. There was a noticeable temperature gradient in the room. It was extremely low at feet level at only about $18^{\circ} \mathrm{C}$, and even at the top of the room temperature was only around $21^{\circ} \mathrm{C}$. This ventilation/heating scenario results in bad air and temperature distribution throughout the room and needs a lot of improvements.

experience higher temperatures. Such a system struggles to ventilate areas around the corners, there is almost no air circulation behind furniture, walls, etc. Furthermore, it is hard to design such a system in real life and guarantee that it will work in all conditions.

Mixing ventilation performed a lot better than natural ventilation. With an inlet fan positioned at the top of the room and an exhaust grille positioned at the bottom of the room, air circulation increases vastly. There are fewer dead spots where there are almost no air circulation and less gradient in temperature. Temperature was especially consistent during summer. LMA value in most of the rooms was just around 15 minutes, while the maximum value was 25 minutes.

Displacement ventilation results show that this system is hard to design. Even when using CFD simulation it required a lot of tweaking to make it work. Air that is supplied has a temperature that is a bit lower than the desired room temperature. The velocity of the airflow also has to be low. Supplied air is spread over the floor and then raises to the top as it is heated by heat sources like people or electric devices. These heat sources create a convective flow to the topo $f$ the room. This airflow brings heat and contaminated air to the top of the room where grill exhausts that air outside. Temperature stratification is much more visible in this case. There are clearly visible layers between warmer and colder air. Furniture that is placed in the middle of the room (table) also causes some issues that results in less effective ventilation. LMA values are similar to mixing ventilation. Areas that are behind the extruding wall have much higher LMA value. These values, in this case, reaches almost 35 minutes.

\section{Discussion}

The indoor environment has a great effect on the comfort and wellbeing of humans. With the age of subjects increasing, the importance of indoor environment quality increases. The effect that bad air quality or thermal comfort can have on the elderly is proven by multiple studies.

This study looked at indoor air quality and thermal comfort in ECC in Lithuania. To our knowledge, this is the first study of this kind in ECC done in Lithuania. Even Worldwide limited amount of such data is available.

Even though our results show that in most cases current conditions in ECC are within national reference levels, they are not optimal for its residents. A new set of norms should be developed for this exact case. Elderly people are at higher risk of damage caused by these factors therefore we can't ignore this issue. More attention should be given to this problem by individual nations as well as EU authorities itself. 
Table. 2 Average temperature in all scenarios during winter and summer as well as LMA values during summer

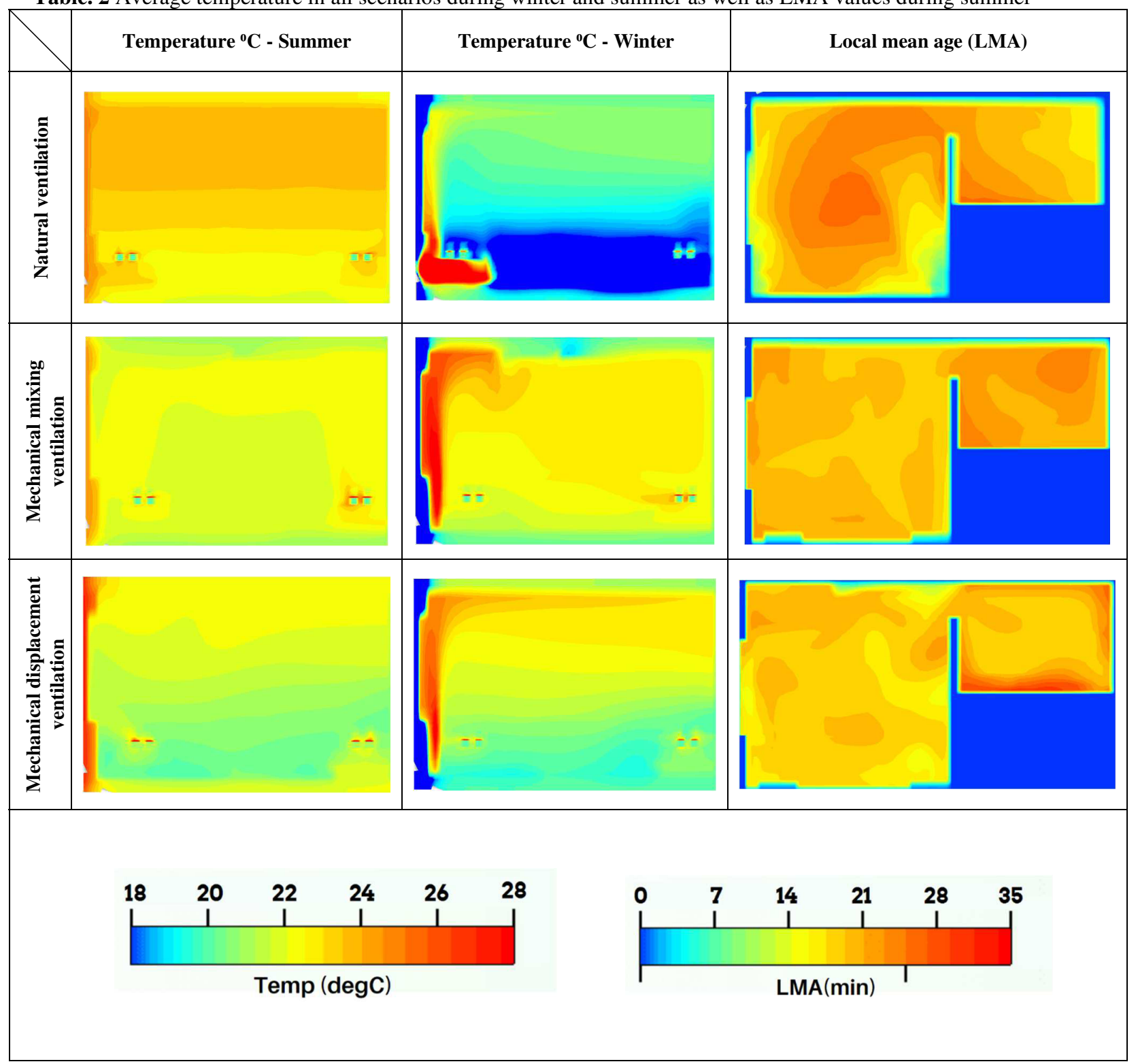

\section{Conclusions}

The results show that even though temperature and $\mathrm{RH}$ are within national reference levels they could be significantly improved to better meet old people needs. Current national norms don't have specific requirements for ECC or elderly people in general. Conditions found in the ECC can cause damage to respiratory health and other illnesses.

CFD simulations shows that mechanical mixing ventilation would the best option out of 3 methods tested: natural ventilation, mechanical displacement and mixing ventilation. When using this method temperature distribution throughout the room is the best, there is no strong temperature stratification.
LMA results also show that even though some of the areas in the aren't getting as much fresh air as the rest of the room, the worst places only had LMA value higher 2 times. The maximum is 25 minutes.

Authors are thankful to the "Kauno Panemune social care center" ECC and all its workers and residents for making this study possible. 


\section{References}

1. Mendes, Ana, et al. "Indoor air quality and thermal comfort-Results of a pilot study in elderly care centers in Portugal." Journal of Toxicology and Environmental Health, Part A 76.4-5 (2013): 333344.M.

2. Klepeis, Neil E., et al. "The National Human Activity Pattern Survey (NHAPS): a resource for assessing exposure to environmental pollutants." Journal of Exposure Science and Environmental Epidemiology 11.3 (2001): 231.

3. Boita, F., et al. "Evaluation of pulmonary function in the elderly. Intergroupe Pneumo Geriatrie SPLFSFGG." Revue des maladies respiratoires $\mathbf{2 3 . 6}$ (2006): 619-628.

4. Bentayeb, Malek, et al. "Higher prevalence of breathlessness in elderly exposed to indoor aldehydes and VOCs in a representative sample of French dwellings." Respiratory medicine 107.10 (2013): 1598-1607.

5. Damiani, Gianfranco, et al. "An ecological study on the relationship between supply of beds in long-term care institutions in Italy and potential care needs for the elderly." BMC health services research 9.1 (2009): 174.

6. Analitis, Antonis, et al. "Effects of cold weather on mortality: results from 15 European cities within the PHEWE project." American journal of epidemiology 168.12 (2008): 1397-1408.

7. Hayashi, Tomohito, et al. "Seasonal influence on blood pressure in elderly normotensive subjects." Hypertension Research 31.3 (2008): 569.

8. R. Corsi, K. Kinney, H. Levin Microbiomes of built environments: 2011 symposium highlights and work-group recommendations, Indoor Air $\mathbf{2 2 . 3}$ (2012): 171-172.

9. Filleul, Laurent, et al. "Difference in the relation between daily mortality and air pollution among elderly and all-ages populations in southwestern France." Environmental Research 94.3 (2004): 249253.

10. Valiathan, R., M. Ashman, and D. Asthana. "Effects of ageing on the immune system: infants to elderly." Scandinavian journal of immunology 83.4 (2016): 255-266.

11. Migliaretti, Giuseppe, Paola Dalmasso, and Dario Gregori. "Air pollution effects on the respiratory health of the resident adult population in Turin, Italy." International journal of environmental health research 17.5 (2007): 369-379.

12. Krems, C., et al. "Lower resting metabolic rate in the elderly may not be entirely due to changes in body composition." European journal of clinical nutrition 59.2 (2005): 255

13. Schellen, Lisje, et al. "Differences between young adults and elderly in thermal comfort, productivity, and thermal physiology in response to a moderate temperature drift and a steady-state condition." Indoor air 20.4 (2010): 273-283.

14. Tsuzuki, K., and T. Ohfuku. "Thermal sensation and thermoregulation in elderly compared to young people in japanese winter season." Indoor Air (2002)

15. HN 125:2011 "Suaugusių asmenu stacionarios socialinès globos ịstaigos: Bendrieji sveikatos saugos reikalavimai". 2011.

16. HN 42:2009 "Gyvenamujų ir visuomeninių pastatų patalpų mikroklimatas"

17. Porritt, Stephen Michael, et al. "Ranking of interventions to reduce dwelling overheating during heat waves." Energy and Buildings 55 (2012): 1627.

18. Lomas, Kevin J., and Stephen M. Porritt. "Overheating in buildings: lessons from research." (2017): 1-18

19. Méndez, C., et al. "Optimization of a hospital room by means of CFD for more efficient ventilation." Energy and Buildings 40.5 (2008): 849-854.

20. Villafruela, José Manuel, et al. "Comparison of air change efficiency, contaminant removal effectiveness and infection risk as IAQ indices in isolation rooms." Energy and Buildings 57 (2013): 210-219.

21. Ho, Son H., Luis Rosario, and Muhammad M. Rahman. "Three-dimensional analysis for hospital operating room thermal comfort and contaminant removal." Applied Thermal Engineering 29.10 (2009): 2080-2092. 